\title{
The effect of dexmedetomidine as an adjuvant to ropivacaine on the bispectral index for supraclavicular brachial plexus block
}

\author{
Youngsuk Kwon, Sung Mi Hwang, Jae Jun Lee, and Jong Ho Kim \\ Department of Anesthesiology and Pain Medicine, Hallym University College of Medicine, Chuncheon, Korea
}

\begin{abstract}
Background: The aim of this study was to evaluate the sedative effect of dexmedetomidine (DEX) added to ropivacaine for supraclavicular brachial plexus block (BPB) using the bispectral index (BIS).

Methods: Sixty patients (American Society of Anesthesiologists physical status 1 or 2, aged 20-65 years) undergoing wrist and hand surgery under supraclavicular BPB were randomly allocated to two groups. Ultrasound-guided supraclavicular BPB was performed with $40 \mathrm{ml}$ of ropivacaine $0.5 \%$ and $1 \mu \mathrm{g} / \mathrm{kg}$ of DEX (Group RD) or $0.01 \mathrm{ml} / \mathrm{kg}$ of normal saline (Group R). The primary endpoint was the BIS change during $60 \mathrm{~min}$ after block. The secondary endpoint was the change in the mean arterial blood pressure (MAP), heart rate (HR), and $\mathrm{SpO}_{2}$ and the onset time and duration of the sensory and motor block.

Results: In Group RD, the BIS decreased significantly until 30 min after the block (69.2 \pm 13.7$)$, but remained relatively constant to $60 \mathrm{~min}(63.8 \pm 15.3)$. The MAP, HR and BIS were significantly decreased compared with Group R. The onset time of the sensory and motor block were significantly faster in Group RD than in Group R. The duration of the sensory and motor block were significantly increased in Group RD.

Conclusions: DEX added to ropivacaine for brachial plexus block induced sedation that corresponds to a BIS value of 60 from which patients are easily awakened in a lucid state. In addition, perineural DEX shortened the onset time and prolonged the duration of the sensory and motor blocks. (Korean J Anesthesiol 2015; 68: 32-36)
\end{abstract}

Key Words: Bispectral index, Brachial plexus, Dexmedetomidine, Ropivacaine.

Corresponding author: Sung Mi Hwang, M.D., Ph.D.

Department of Anesthesiology and Pain Medicine, Chuncheon Sacred

Heart Hospital, 77 Sakju-ro, Chuncheon 200-704, Korea

Tel: 82-33-240-5155, Fax: 82-33-251-0941

E-mail: h70sm@hallym.or.kr

Received: September 16, 2014.

Revised: 1st, October 23, 2014; 2nd, November 11, 2014.

Accepted: November 18, 2014.

Korean J Anesthesiol 2015 February 68(1): 32-36

http://dx.doi.org/10.4097/kjae.2015.68.1.32

\section{Introduction}

The brachial plexus block is a regional anesthetic technique used for upper limb surgeries. Adjuvant drugs are often added to local anesthetics for several reasons [1,2]. Like clonidine, the a-2 receptor agonist dexmedetomidine (DEX) has been reported to have a rapid onset time, to prolong the duration of local anesthetics, and to increase the quality of analgesia in a regional block [3-5]. In addition, intravenous DEX provides sedation that is easily reversed with no respiratory depression $[5,6]$. Some

(c) This is an open-access article distributed under the terms of the Creative Commons Attribution Non-Commercial License (http://creativecommons.org/ licenses/by-nc/3.0/), which permits unrestricted non-commercial use, distribution, and reproduction in any medium, provided the original work is properly cited. 
studies have investigated the effect of DEX on sedation when added to local anesthetics for brachial plexus block. However, given the type of sedation induced by DEX, sedation scoresincluding the Ramsay sedation score and OAA/S (Observer's Assessment of the Alertness/Sedation Scale)-are not appropriate for evaluation of the objective sedation state.

To these ends, we performed a prospective and double blinded study that used the bispectral index (BIS) to analyze the effect of DEX on sedation when added to ropivacaine for supraclavicular brachial plexus block.

\section{Materials and Methods}

After receiving approval from the Institutional Review Board of our hospital, we obtained informed consent from each enrolled patient. Inclusion criteria were patients aged 20-65 years, who were to undergo forearm and hand surgery under supraclavicular brachial plexus block. Patients with a history of hypertension, peripheral neuropathy, cerebrovascular disease, psychiatric disease, or coagulopathies were excluded.

No premedication was given. On arrival in the operating room, patients were monitored by noninvasive blood pressure, electrocardiogram, peripheral oxygen saturation $\left(\mathrm{SpO}_{2}\right)$, heart rate (HR), and BIS. Each patient was administered $3 \mathrm{~L} / \mathrm{min}$ supplemental oxygen through a nasal cannula. Sealed envelopes were used to randomly assign each patient to receive either $40 \mathrm{ml}$ of ropivacaine $0.5 \%$ with $0.01 \mathrm{ml} / \mathrm{kg}$ normal saline (Group R, $\mathrm{n}=$ 30 ), or $40 \mathrm{ml}$ of ropivacaine $0.5 \%$ with $1 \mu \mathrm{g} / \mathrm{kg}$ DEX (Group RD, $\mathrm{n}=30$ ) in a double-blinded fashion. A supraclavicular brachial plexus block was performed with the patient in the supine position and the head turned away from the side that received the block, which was performed by an experienced anesthesiologist. After surgical preparation of the area, a 22-gauge short-beveled, Teflon-coated needle (Stimuplex ${ }^{\circledR}$ A, B.Braun, Melsungen, Germany) attached to a nerve stimulator (Stimuplex ${ }^{\circledR}$ Dig RC, B.Braun, Melsungen, Germany) was inserted under real-time ultrasound guidance using an in-plane approach. Ultrasound imaging was performed using a SonoSite (Sonosite, Inc., Bothell, WA, USA) with an HFL 38x/13-6 MHz transducer. After careful aspiration, $40 \mathrm{ml}$ of solution containing either normal saline or DEX were injected. We selected the BIS change as the primary endpoint, and the onset time and duration of the blocks, and change in the mean arterial pressure (MAP), HR, and respiratory depression were secondary endpoints.

Sensory and motor blocks were assessed each minute after the injection. Sensory block was defined as a loss of feeling in all nerve territories (radial, ulnar, median and musculocutaneous nerves), assessed using the pinprick test. Onset time was defined as the time interval between the end of solution injection and onset of sensory block. Motor block was assessed and graded as follows: grade $1=$ ability to flex and extend the forearm; grade $2=$ ability to flex or extend only the wrist and fingers; grade 3 $=$ ability to flex or extend only the fingers; grade $4=$ inability to move the forearm, wrist, and fingers [7]. The onset time was considered when Grade 3 was achieved. The duration of sensory block was evaluated every hour after the operation and was defined as the time interval between the end of solution injection and the recovery of feeling in all nerve territories. The motor block duration was also evaluated each hour after the operation and was defined as the time interval between the end of solution injection and the recovery of wrist movement. The MAP, HR, $\mathrm{SpO}_{2}$ and BIS were monitored for $60 \mathrm{~min}$ after the end of the local anesthetic injection and recorded at 10 min intervals.

Hypotension was defined as less than $80 \%$ of the preanesthetic level. Bradycardia was defined as $\mathrm{HR}<50$ beats/min and was treated with $0.5 \mathrm{mg}$ intravenous atropine. Patients were asked whether they remembered their experience in the operating room immediately after the operation and $24 \mathrm{~h}$ later.

The sample sizes were calculated a power analysis ( $\alpha=0.05$, $\beta=0.8$ ) based on the assumption that the BIS would decrease by 20 (SD 25) at $60 \mathrm{~min}$ after the block in Group RD; considering a $10 \%$ loss rate, at least 27 patients were needed in each group.

Data are expressed as numbers of patients or the mean \pm standard deviation. All of the analyses were performed using the SPSS software (ver. 12; SPSS, Chicago, IL, USA). Independent $\mathrm{t}$-test was used for the comparison of the onset time and duration of the blocks. After confirming the violation of sphericity assumption $(\mathrm{P}<0.001)$ using Mauchly's test, we adjusted the within-subject statistics in RMANOVA with the GreenhouseGeisser adjustment factor for comparison of the changes of the BIS, MAP and HR. Greenhouse-Geisser-adjusted P values $<0.05$ were accepted as indicative of statistical significance.

\section{Results}

The demographic data were similar between the two groups (Table 1). In Group RD, the BIS decreased continuously until 30 min after the block $(69.2 \pm 13.7)$ but remained relatively constant to $60 \min (63.8 \pm 15.3)$. The BIS was significantly lower than that for Group R throughout the monitoring period (Fig. 1; Greenhouse-Geisser-adjusted P value $(\varepsilon=0.429)<0.001)$. The onset time of sensory and motor block in Group RD was shorter than in Group R, and the durations of sensory and motor block were increased in Group RD compared with Group R (Table 2; $\mathrm{P}<0.05)$.

The BIS, MAP and HR were unchanged in Group R. The MAP of Group RD decreased until 30 min after the block and was significantly lower than in Group R (Table 3; GreenhouseGeisser-adjusted P value $(\varepsilon=0.464)<0.001)$. The HR decreased continuously until $20 \mathrm{~min}$ after the block and then remained rel- 
atively constant to $60 \mathrm{~min}$ in Group RD (Table 3; GreenhouseGeisser-adjusted P value $(\varepsilon=0.370)<0.001)$. Seven patients in Group RD had bradycardia, six of whom were within $20 \%$ of

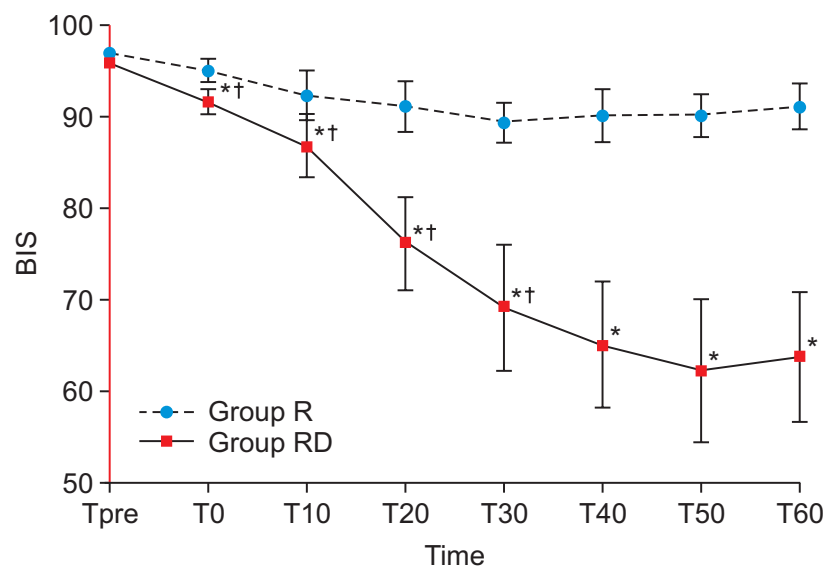

Fig. 1. Changes in the BIS. T: time (min) before and after brachial plexus block, Group RD received $40 \mathrm{ml}$ of ropivacaine $0.5 \%$ with $1 \mu \mathrm{g} / \mathrm{kg}$ of dexmedetomidine, Group R received $0.01 \mathrm{ml} / \mathrm{kg}$ of normal saline instead of dexmedetomidine. *Greenhouse-Geisser-adjusted P $<0.001$ compared with Group R. ${ }^{\dagger}$ Greenhouse-Geisser-adjusted P $<0.001$ compared with the preceding step in each group.

Table 1. Demographic Data

\begin{tabular}{lcc}
\hline & $\begin{array}{c}\text { Group R } \\
(\mathrm{n}=30)\end{array}$ & $\begin{array}{c}\text { Group RD } \\
(\mathrm{n}=30)\end{array}$ \\
\hline Age $(\mathrm{yr})$ & $44.5 \pm 14.5$ & $40.3 \pm 13.9$ \\
Sex $(\mathrm{M} / \mathrm{F})$ & $17 / 13$ & $20 / 20$ \\
Height $(\mathrm{cm})$ & $165.7 \pm 10.1$ & $167.5 \pm 9.7$ \\
Weight $(\mathrm{kg})$ & $65.3 \pm 10.8$ & $64.1 \pm 12.4$ \\
Duration of surgery $(\mathrm{min})$ & $70.2 \pm 24.8$ & $74.5 \pm 34.4$ \\
Type of surgery & & \\
$\quad$ Wrist/hand & $14 / 16$ & $17 / 13$ \\
\hline
\end{tabular}

Values are expressed as the means \pm SD or numbers of patients or surgeries. Group RD received $40 \mathrm{ml}$ of ropivacaine $0.5 \%$ with $1 \mu \mathrm{g} / \mathrm{kg}$ of dexmedetomidine for supraclavicular BPB. Group R received $0.01 \mathrm{ml} / \mathrm{kg}$ of normal saline instead of dexmedetomidine. the preanesthetic value, so treatment was needed in only one patient.

All patients had $\mathrm{SpO}_{2}>98 \%$, so no comparison was performed. All patients remembered that remembered their experience in the operating room immediately after the operation and $24 \mathrm{~h}$ later.

\section{Discussion}

The ideal regional block has a rapid onset and a long duration of analgesia, while providing high-quality analgesia without side effects. To achieve this, several adjuvants are added to local anesthetics. Recently, DEX has been reported as an effective adjuvant for regional anesthetic agents. When given intravenously after or before spinal anesthesia, DEX increases the duration of spinal anesthesia $[5,6]$. When administered as an adjuvant to local anesthetics for peripheral nerve block and plexus block, DEX shortens the onset time of the block, prolongs the duration of the block, and increases the quality of analgesia without neurologic sequelae. The analgesic effect is caused by enhancement of the hyperpolarization-activated cation current $[8,9]$. Another advantage of DEX is that it induces natural sleep from which

Table 2. Onset Time and Duration of the Sensory and Motor Blocks

\begin{tabular}{ccc}
\hline & $\begin{array}{c}\text { Group R } \\
(\mathrm{n}=30)\end{array}$ & $\begin{array}{c}\text { Group RD } \\
(\mathrm{n}=30)\end{array}$ \\
\hline Onset time (min) & & \\
Sensory block & $8.3 \pm 4.4$ & $5.1 \pm 3.4^{*}$ \\
Motor block & $13.0 \pm 5.6$ & $8.9 \pm 3.8^{*}$ \\
Duration (min) & & \\
Sensory block & $654.8 \pm 145.2$ & $869.1 \pm 120.7^{*}$ \\
Motor block & $606.3 \pm 153.7$ & $768.7 \pm 151.8^{*}$ \\
\hline
\end{tabular}

Values are expressed as the means \pm SD. Group RD received $40 \mathrm{ml}$ of ropivacaine $0.5 \%$ with $1 \mu \mathrm{g} / \mathrm{kg}$ of dexmedetomidine for supraclavicular BPB. Group R received $0.01 \mathrm{ml} / \mathrm{kg}$ of normal saline instead of dexmedetomidine. ${ }^{*} \mathrm{P}<0.05$ compared with Group $\mathrm{R}$.

Table 3. Changes in the MAP and HR

\begin{tabular}{|c|c|c|c|c|}
\hline & \multicolumn{2}{|c|}{ MAP (mmHg) } & \multicolumn{2}{|c|}{ HR (beats/min) } \\
\hline & Group R & Group RD & Group R & Group RD \\
\hline Tpre & $107.7 \pm 10.8$ & $104.5 \pm 14.8$ & $74.0 \pm 11.6$ & $70.0 \pm 12.5$ \\
\hline T0 & $107.9 \pm 12.7$ & $101.2 \pm 12.5^{*, \dagger}$ & $74.2 \pm 12.0$ & $68.5 \pm 12.1$ \\
\hline $\mathrm{T} 10$ & $111.5 \pm 13.1$ & $98.1 \pm 13.7^{*, \dagger}$ & $76.8 \pm 11.3$ & $65.9 \pm 11.9^{*, \dagger}$ \\
\hline $\mathrm{T} 20$ & $111.2 \pm 14.2$ & $94 \pm 12.9^{*, \dagger}$ & $77.0 \pm 12.5$ & $62.2 \pm 10.9^{*,+}$ \\
\hline T30 & $107.2 \pm 12.7$ & $88.9 \pm 10.4^{*, \dagger}$ & $74.9 \pm 11.2$ & $60.7 \pm 11.3^{*}$ \\
\hline T40 & $105.1 \pm 11.1$ & $88.1 \pm 10.3^{*}$ & $74.3 \pm 11.8$ & $58.9 \pm 10.2^{*}$ \\
\hline T50 & $105.4 \pm 12.2$ & $88.1 \pm 10.5^{*}$ & $74.5 \pm 12.8$ & $59.4 \pm 10.2^{*}$ \\
\hline T60 & $104.9 \pm 10.9$ & $86.6 \pm 8.7^{*}$ & $74.6 \pm 11.4$ & $59.1 \pm 10.4^{*}$ \\
\hline
\end{tabular}

Values are expressed as the means \pm SD. Group RD received $40 \mathrm{ml}$ of ropivacaine $0.5 \%$ with $1 \mu \mathrm{g} / \mathrm{kg}$ of dexmedetomidine for supraclavicular BPB. Group $\mathrm{R}$ received $0.01 \mathrm{ml} / \mathrm{kg}$ of normal saline instead of dexmedetomidine. MAP: mean arterial pressure, HR: heart rate, T: time (min) before and after the brachial plexus, *Greenhouse-Geisser-adjusted $\mathrm{P}<0.001$ compared with Group R, ${ }^{\dagger}$ Greenhouse-Geisser-adjusted $\mathrm{P}<0.001$ compared with the preceding step in each group. 
patients can be readily awakened and is associated with better patient cooperation [10]. The mechanism of inducing natural sleep is the action of DEX on the locus ceruleus [11].

In this prospective, randomized, double-blinded trial, $1 \mu \mathrm{g} / \mathrm{kg}$ of DEX added to ropivacaine induced natural sedation and decreased the BIS value to $\sim 60$. This BIS value indicates a state of moderate-to-deep sedation or hypnosis; however, patients were easily awakened by mild stimuli. In addition, perineural DEX decreased the onset time of the sensory and motor blocks and increased the duration of each block compared with ropivacaine alone. The DEX-related adverse effects are hypotension, bradycardia and respiratory depression. In a systemic review and meta-analysis, the incidence of hypotension in the brachial plexus block was similar to that of the control group and the incidence of bradycardia was higher in the DEX group (7\% vs $0 \%$ ). However, this bradycardia was transient and well reversed by atropine injection [2]. In the present study, although the MAP and HR were deceased in Group RD, only one patient needed treatment and was successfully reversed.

Considering that DEX induces easily awakened sleep, sedation scores such as the Ramsay sedation score and the OAA/S (Observer's Assessment of the Alertness/Sedation Scale) are not appropriate methods of exact and objective evaluation of the sedation state. Wang et al. [12] evaluated the effects of different loading doses of DEX on the BIS under stepwise propofol targetcontrolled infusion and recommended that no clinical sedation scoring system be used to avoid disturbing the recorded BIS value. They preferred invasive blood pressure measurements over noninvasive blood pressure. Even noninvasive blood pressure measurements can disturb the sleeping patient, affecting the BIS value.

While performing this study, we took care to keep the operating room quiet, protecting the patient from all physical and sound stimuli. All measurements were recorded until $10 \mathrm{~min}$ before the end of surgery considering the messy situation at the end of surgery.

Before or after regional anesthesia, some patients require sedation intraoperatively for anxiolysis. Intravenous midazolam is commonly used for sedation. However, some patients complained of an inability to sleep after midazolam injection. Retrograde amnesia can also occasionally lead to confusion. Benzodiazepines are also rarely associated with a paradoxical reaction characterized by restlessness and agitation, a phenomenon that has been reported since the introduction of benzodiazepines $[10,13]$. Given these drawbacks, DEX is considered a more appropriate adjuvant for regional blocks. Although DEX decreases the BIS value corresponding to general anesthesia, patients can be easily awakened and memory function is unaffected without confusion. This yields better cooperation from the patient during surgery and recovery.

In this study, all patients enrolled in Group $\mathrm{RD}$ recalled the process of anesthesia and the operation and that they were sleeping. However, DEX was also associated with immediate, but not retrograde, memory impairment. Hall et al. [5] showed that volunteers sedated with intravenous DEX could be easily awakened and could perform a cognition test that included a digit symbol substitution test and a memory recall test but, they had difficulty in recalling the tests until 4 hours after termination of the infusion. Unlike with midazolam, they recalled the tests given prior to administration of DEX.

In conclusion, perineural DEX for supraclavicular brachial plexus block induces sedation that corresponds to a BIS value of 60 from which patients are easily awakened in a lucid state, resulting in better cooperation with the surgical team during surgery and recovery.

\section{References}

1. Brummett CM, Williams BA. Additives to local anesthetics for peripheral nerve blockade. Int Anesthesiol Clin 2011; 49 : 104-16.

2. Abdallah FW, Brull R. Facilitatory effects of perineural dexmedetomidine on neuraxial and peripheral nerve block: a systemic review and meta-analysis. Br J Anaesth 2013; 110: 915-25.

3. Esmaoglu A, Yegenoglu F, Akin A, Turk CY. Dexmedetomidine added to levobupivacaine prolongs axillary brachial plexus block. Anesth Analg 2010; 111: 1548-51.

4. Marhofer D, Kettner SC, Marhofer P, Pils S, Weber M, Zeitlinger M. Dexmedetomidine as an adjuvant to ropivacaine prolongs peripheral nerve block: a volunteer study. Br J Anaesth 2012; 110: 438-42.

5. Hall JE, Uhrich TD, Barney JA, Arain SR, Ebert TJ. Sedative, amnestic, and analgesic properties of small-dose dexmedetomidine infusions. Anesth Analg 2010; 90: 699-705.

6. Jung SH, Lee SK, Lim KJ, Park EY, Kang MH, Lee JM, et al. The effects of single-dose intravenous dexmedetomidine on hyperbarix bupivacaine spinal anesthesia. J Anesth 2013: 27: 380-4.

7. Borgeat A, Ekatodramis G, Dumont C. An evaluation of the infraclavicular block via a modified approach of the Raj technique. Anesth Analg 2001; 93: 436-41.

8. Fritsch G, Danninger T, Allerberger K, Tsodikov A, Felder TK, Kapeller M, et al. Dexmedetomidine added to ropivacaine extends the 
duration of interscalene brachial plexus blocks for elective shoulder surgery when compared with ropivacaine alone: a single-center, prospective, triple-blind, randomized controlled trial. Reg Anesth Pain Med 2014; 39: 37-47.

9. Brumett CM, Norat MA, Palmisano JM, Lydic R. Perineural administration of dexmedetomidine in combination with bupivacaine enhanced sensory and motor blockade in sciatic nerve block without inducing neurotoxicity in rat. Anesthesiology 2008; $109: 502-11$.

10. Fan TW, Ti LK, Islam I. Comparison of dexmedetomidine and midazolam for conscious sedation in dental surgery monitored by bispectral index. Br J Oral Maxillofac Surg 2013; 51: 428-33.

11. MacDonald E, Scheinin M. Distribution and pharmacology of alpha 2-adrenoceptors in the central nervous system. J Physiol Pharmacol 1995; 46: 241-58.

12. Wang T, Ge S, Xiong W, Zhou P, Cang J, Xue Z. Effects of different loading doses of dexmedetomidine on bispectral index under stepwise propofol target-controlled infusion. Pharmacology 2013; 91: 1-6.

13. Robin C, Trieger N. Paradoxical reactions to benzodiazepines in intravenous sedation: a report of 2 cases and review of the literature. Anesth Prog 2002; 49: 128-32. 